\title{
Perancangan Kotak Aktivitas ABC Petualang Sebagai Media Bermain dan Perkembangan Dasar Anak Pra-Sekolah
}

\author{
Diajeng Rachmi Andini dan Raditya Eka Rizkiantono \\ Departemen Desain Komunikasi Visual, Fakultas Arsitektur Desain dan Perancangan \\ Institut Teknologi Sepuluh Nopember (ITS) \\ e-mail: ajengdra24@gmail.com / ekaindian007@gmail.com
}

\begin{abstract}
Abstrak-Kehadiran gadget seperti tablet, smartphone, komputer dan televisi semakin mempermudah akses informasi, hiburan, serta pendidikan bagi umat manusia.Terlepas dari berbagai kelebihan yang dimiliki oleh gadget, terdapat pula dampak buruk dari penggunaan gadget pada anak. Perancangan kotak aktivitas dengan ambience visualyang ada di Indonesia adalah sebuah alternatif media pembelajaran dan permainan bagi anak dimasa keemasannya. Perancangan ini dibuat dengan tujuan membantu anak untuk mengembangkan aspek dan kemampuan dasar seperti kreativitas, bahasa, kognitif dan psikomotorik, serta dapat membantu anak mengenal lingkungan yang ada di Indonesia melalui konten dan tampilan visualnya.

Hasil dari beberapa metode penelitian kemudian diterjemahkan menjadi konsep kotak aktivitas ABC Petualang. Konsep tersebut menghasilkan ilustrasi ambience yang ada di Indonesia serta tiga karakter utama yaitu Acil si kancil, Bao-bao si kerbau dan Cici si kelinci dengan gaya ilustrasi anak digital. Konsep desain dan ilustrasi kemudian diterapkan dengan proses prototyping kotak aktivitaspada seri pulau Sumatera dan Jawa yang berisi masing-masing satu buah buku aktivitas yang menjabarkan isi pulau tersebut disertakan 6 aktivitas yang mendukung aspek-aspek perkembangan dasar anak seperti kreativitas, kognitif, psikomotorik, dan bahasa.

Penelitian ini menghasilkan sebuah media edukasi dan permainan non-gadget untuk anak usia dini yang menarik dan memiliki tujuan agar anak-anak dapat mengembangkan kemampuan dasarnya serta mengenali lingkungan sekitarnya. Dimasa mendatang, kedepannya diharapkan agar dilakukan penelitian yang berhubungan dengan tema media yang membantu mengembangkan kemampuan dasar anak lainnya.
\end{abstract}

Kata Kunci: kotak aktivitas, ambience Indonesia, anak usia 4-6 tahun

\footnotetext{
Abstract-The existence of gadgets such as tablets, smart phones, computers and television increasingly facilitates access to information, entertainment, and education for humanity. Apart from the various advantages possessed by gadgets, there are also adverse effects from the use of gadgets in children. The design of the activity box with visual ambience in Indonesia is an alternative learning media and game for children in its golden age. This design was made with the aim of helping children to develop basic aspects and abilities such as creativity, language, cognitive and psychomotor, and can help children recognize the environment in Indonesia through their content and visual appearance.

The results of several research methods were then translated into the concept of "ABC Petualang Nusantara" activity concept. The concept produced ambience illustrations in Indonesia as well as three main characters namely Acil the mouse-deer, Bao-bao the buffalo and Cici the rabbit in the style of a digital child illustration. The design and illustration concepts are then applied with the prototyping of activity boxes on the Sumatran and Javanese series containing each one activity book that describes
}

the contents of the island. There are 6 activities that support aspects of children's basic development such as creativity, cognitive, psychomotor, and language.

This research produced an interesting medium of education and non-gadget games for early childhood with the aim that children can develop their basic abilities and recognize their surroundings. In the future, future research is expected to be carried out relating to media themes that help develop other children's basic abilities.

Keywords: activity box, Indonesian ambiance, children aged 4-6 years

\section{PENDAHULUAN}

A. Latar Belakang

Berkembangnya gadget kini semakin membuat penggunanya merambah ke anak-anak.Menurut penelitian seorang psikolog dan playtheraphist Fakultas Psikologi Universitas Indonesia Dra. Mayke S. Tedjasaputra, Psi, M.Si, kesempatan seorang anak untuk bermain dengan orang tuanya semakin minim karena sibuk bekerja dan memilih gadet sebagai pilihan alternatif media agar anak tetap bisa terhibur tanpa andil orang tua di dalamnya[1].

Terlepas dari kelebihannya, berbagai penelitian telah dilakukan mengenai dampak gadet pada anak. Mulai dari kedokteran maupun dunia psikolog. Menurut Dr. Sigman dalam konferensi Royal College of Paediatrics and Child Health $(R C P C H)$ di Glasgow, dopamine hormone akan dikeluarkan oleh tubuh kita saat menatap layar gadet yang membuat anak-anak kecanduan untuk terus bermain gadget. Pengaruh lain yang ditimbulkan oleh penggunanan gadget berlebihan pada anak adalah dapat melemahkan pertumbuhan motorik pada anak dan menghalangi perkembangan lain seperti afektif dan kognitif .

Keterlambatan perkembangan pada anak disebabkan oleh dua faktor yaitu faktor nature dan nurture. Faktor nature disebabkan oleh faktor keturunan (genetik) dan faktor nurture disebabkan oleh faktor luar yang berpengaruh terhadap otak bayi saat masih dalam kandungan atau saat anak-anak. Perkembangan masa anak meliputi kemampuan berbahasa, kreativitas, kesadaran sosial, emosional dan intelegensi akan berjalan sangat cepat. Menurut wawancara yang dilakukan oleh penulis pada klinik playtherapist, gadget adalah penyebab terebesar dari faktor nurture. Sebuah survei yang dilakukan oleh Common Sense Media mengungkapkan bahwa 38 persen anak di bawah 2 tahun telah menggunakan gadget bahkan sebelum mereka dapat berbicara atau berjalan [2 dan 3].

Padahal ada banyak aktivitas yang dapat membantu anak mengembangkan kemampuan dasarnya. Melakukan aktivitas untuk mengembangkan kemampuan anak tidak melulu 
memerlukan area yang luas.Aktivitas kecil seperti membaca, bermain puzzle, bermain congklak pun bisa dijadikan alternatif kegiatan yang dapat dikerjakan didalam ruangan dan dapat menstimulasi perkembangan anak. Saat ini sudah banyak media edukasi yang dapat mendukung anak untuk belajar secara informal.Aktivitas pada anak dapat dilakukan secara individual maupun berkelompok, namun guru atau orang tua harus tetap ikut mengawasi. Karena usia anak membutuhkan peran orang tua untuk membimbing dan mengawasi anaknya.

Kotak aktivitas adalah sebuah media bagi anak berupa wadah yang berisikan beberapa aktivitas kecil dengan basis edukasi dan berfungsi sebagai sarana yang dapat membantu merangsang perkembangan dasar anak ${ }^{6}$. Kotak aktivitas dapat digunakan didalam maupun luar ruangan. Belajar akan terasa menyenangkan pada anak balita apabila dilakukan dengan cara bermain dan beraktifitas yang menyenangkan, karena pada dasarnya usia balita adalah usia bermain.

\section{B. Rumusan Masalah}

Bagaimana merancang kotak aktivitas sebagai media dengan konten yang bermanfaat untuk merangsang kemampuan dasar pada anak usia 4-6 tahun dengan berbasis konten visual yang ada di Indonesia?

\section{Batasan Masalah}

Batasan masalah dalam perancangan Kotak aktivitas ini meliputi :

1. Merancang Kotak aktivitas dengan konten aktivitas yang bermanfaat bagi perkembangan dasar anak.

2. Perancangan pada media ini mengandung ambience visual yang ada di Indonesia, sehingga dapat dinikmati oleh seluruh kalangan.

3. Aktivitas yang akan dipakai, sebelumnya dikonsultasikan dengan psikolog anak maupun playtherapist.

4. Bahan material yang digunakan mudah didapatkan di Indonesia, khususnya di Pulau Jawa sehingga dapat diproduksi secara massal.

\section{TINJAUAN PUSTAKA}

\section{A. Teori Perkembangan Anak}

Anak-anak usia dini adalah rentang usia dari waktu ia lahir hingga usia 6 tahun. Pada masa anak usia inilah diberikan rangsangan berupa rangsangan rohani dan jasmani. Usia dini menentukan bagi anak dalam mengembangan potensinya yaitu dari umur 0-8 tahun. Pastinya usia ini hanya datang sekali dan tidak terulang lagi dan hal ini sangat menentukan perkembangan kualitas manusia hingga usia ini disebut sebagai usia keemasan (the golden age) [4 dan 5].

\section{B. Media Pendukung Perkembangan Anak}

Association of Education and Communication Technology memberikan batasan bahwa media sebagai segala bentuk dan saluran yang digunakan untuk menyalurkan pesan/ informasi. Segala alat fisik yang dapat menyajikan pesan serta merangsang anak untuk belajar merupakan definisi media (Gagne, 1970). Media memiliki kegunaan untuk mengatasi keragaman latar belakang anak sehingga dapat memberikan perangsang, pengalaman dan menimbulkan persepsi yang sama [6,7 dan 8$]$.

\section{Alat Permainan Edukatif}

Alat permainan adalah semua alat bermain yang digunakan oleh anak untuk memenuhi naluri bermain anak, sehingga menghasilkan pengertian memberikan informasi, kesenangan, danm mampu mengembangkan seluruh aspek.

\section{METODELOGI DESAIN}

\section{A. Alur PEnelitian}

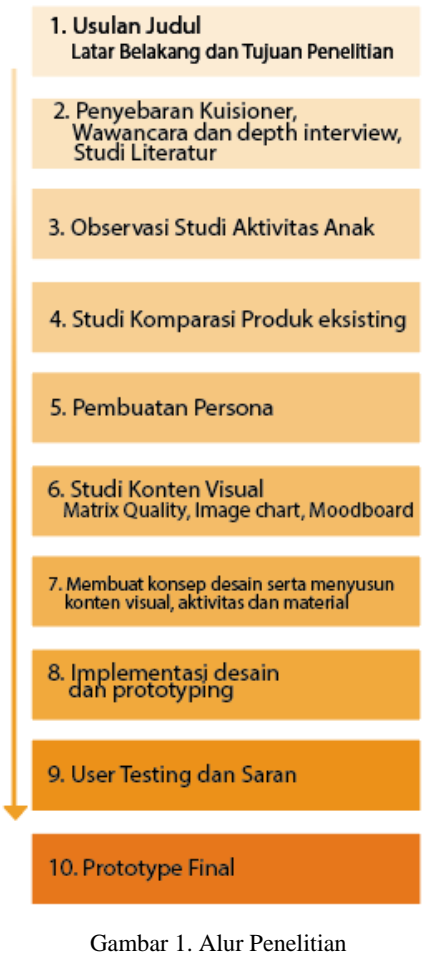

Berdasarkan diagram alur penelitian, penelitian ini dilakukan dalam 10 tahapan yang berjalan melalui bertahap, yaitu sebagai berikut:

\section{Tahap ke-1}

Tahapan ini meliputi kelayakan judul yang disesuaikan pada fenomena yang sedang terjadi. Pada tahap pertama yaitu melakukan penyebaran kuisioner dan wawancara untuk memperkuat fenomena pada latar belakang permasalahan, serta alasan penggunaan media kotak aktivitas sebagai media hiburan dan pembelajaran bagi anak usia 4-6 tahun dengan melakukan mendalami studi refrensi terhadap produk yang sudah ada.

\section{Tahap ke-2}

Melakukan wawancara dan depth interview kepada ahli playtherapist dan psikolog anak.

\section{Tahap ke-3}

Studi komparasi media eksisting yang berhubungan dengan perkembangan anak, seperti kotak aktivitas yang sudah ada. Tahapan ini dilakukan untuk mendapatkan konsep desain, konten aktivitas dan material yang akan digunakan untuk perancangan kotak aktivitas ini.

\section{Tahap ke-4}

Pada tahapan ini observasi berupa studi aktivitas yang dilakukan oleh target user dan melakukan studi persona kepada target market. 


\section{Tahap ke-5}

Melakukan studi konten visual menggunakan metode Matrix Quality dan image chart untuk mendalami konten visual yang tepat untuk anak usia dini.

\section{Tahap ke-6}

Mengolah data yang dihasilkan dari tahapan ke-1, ke-2, ke-3 dan ke-4 menjadi data user persona yang akan dijadikan acuan desain.

\section{Tahap ke-7}

Membuat konsep desain serta menyusun konten visual, aktivitas dan material yang akan digunakan berdasarkan tahapan ke 1-6.

\section{Tahap ke-8}

Membuat Prototype dari produk dan melakukan user review pada target user.

\section{Tahap ke-9}

Rumusan dan rekomendasi dari target user.

\section{Tahap ke-10}

Membuat Prototype final.
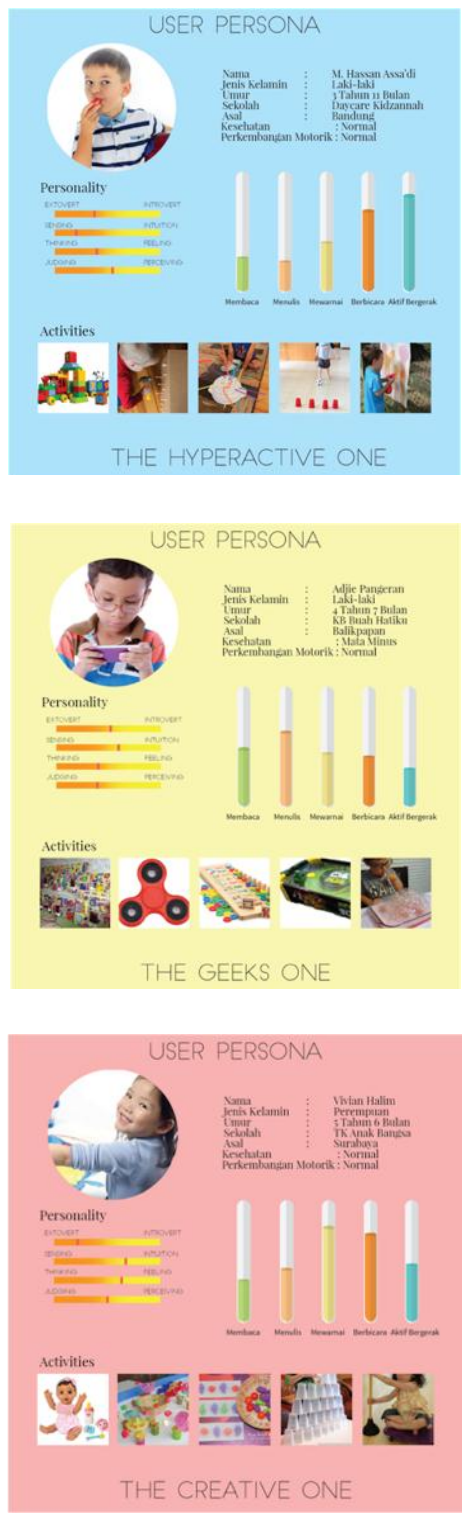

Gambar 2. User Persona
B. Hasil dan Analisa Penggalian Data

1 Kuisioner Jumlah Responden : 75 Responden Metode Penyeberan : Penyebaran Online Waktu Penyebaran : 22-29 Oktober 2017 Hasil dari Kuisioner :

a. Responden menggunakan berbagai media untuk mendidik dan menghibur anaknya. Sebanyak $84,4 \%$ responden menggunakan media mainan edukasi, 57\% gadget, $56 \%$ buku cerita, $48 \%$ buku interaktif dan kurang dari $10 \%$ memilih alam.

b. Respon penggunaan gadget pada anak para responden adalah $51 \%$ jarang, $21 \%$ sering dan sisanya belum memberikan gadget pada anak.

2 Persona

User Persona (gambar 2) adalah persona yang digunakan untuk memproyeksikan target user dari kotak aktivitas.Tujuan dari pembuatan user persona ini adalah untuk menentukan konten dari produk kotak aktivitas ini.

3 In-Depth Interview

In-depth Interview (wawancara mendalam) merupakan metode pengumpulan data yang digunakan dalam penelitian kualitatif.Narasumbernya adalah para ahli pakar yang bersangkutan dalam perancangan ini,yaitu playtherapist dan psikolog anak.

\section{Studi Eksisting}

Studi eksisting bertujuan untuk mempelajari produk serupa atau yang terkait untuk kemudian dievaluasi dan dijadikan bahan pertimbangan dalam melalukan. Beberapa eksisting yang dipelajari adalah yang berhubungan dengan Activity box atau busy box seperti Genius Box, Little Passport, ElHana First Busy Bag, dan Menthilis Project.

\section{KONSEP DAN IMPLEMENTASI DESAIN}

\section{A.Target Pengguna}

Target utama pengguna kotak aktivitas adalah anak-anak usia 4-6 tahun pada jenis kelamin laki-laki maupun perempuan. Pemilihin usia 4-6 tahun ini adalah karena kelompok umur anak ini berada diantara kelompok umur dimana anak sudah dapat bermain secara parallel play dan usia dimana anak belum memasuki Sekolah.

1234567890 A B C DEFG H J KL MNOP QRST UV W XYZ \{Brudy Bunch\}

\section{0 \\ ABCDEFGHIJKLMNOP QRSTUVWXYZ \\ \{Letter for learners\}}

B. Keyword

Gambar 3. Pemilihan font

$\mathrm{ABC}$ Petualang nusantara terdiri dari 6 seri Kotak aktivitas dimana setiap tema-nya diangkat dari pengetahuan budaya, 
kuliner, flora, fauna, ikon dari setiap kota yang ada di Indonesia. Konsep desain dan ilustrasi yaitu ceria, anak-anak dan menggunakan warna yang cerah.

\section{Font}

Pemilihan font Letter for learners didasarkan aspek keterbacaan yang baik oleh font hingga ukuran yang terkecil. Selain itu jenis font Brudy Bunch dipilih untuk merepresentasikan keyword modern dengan tampilan font yang dekoratif dan memberikan kesan ceria serta lucu (Gambar 3)..

\section{D.Logo}

Logo utama yang didesain menjadi pedoman desain ilustrasi karakter dan ambience aktivitas (Gambar 4).

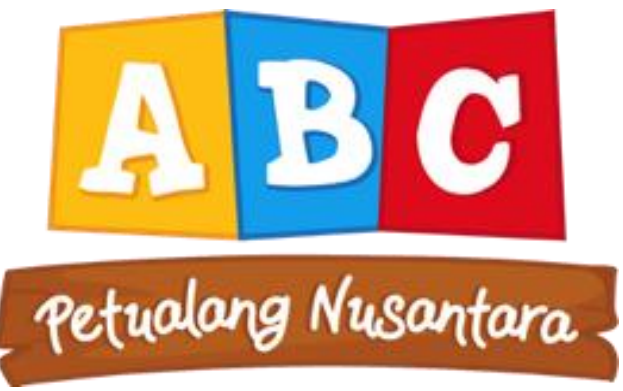

Gambar 4. Logo ABC Petualang Nusantara

\section{E. Konten Buku Aktivitas}

Kotak ABC Petualang Nusantara terdiri dari satu buah buku aktivitas yang menceritakan tiga karakter utama yang berkeliling pulau yang ada di Indonesia. Ketiga karakter tersebut bertemu dengan hewan-hewan endemik dan mendapatkan pengalaman baru (Tabel 1).

\section{F. Konten kotak aktivitas}

Pemetaan konten kotak aktivitas dilakukan untuk merancang ilustrasi dan material yang akan digunakan.Data kebutuhan konten kotak aktivitas didapatkan dari pembuatan moodboard yang dipetakan dari jenis dan tujuan kegiatan untuk mengembangkan kemampuan dasar anak (Tabel 2).

\section{G.Skema Warna}

Warna yang digunakan pada output perancangan ini adalah warna umum dari warna primer dan sekunder. Gabungan warna keduanya dimaksudkan menyeimbangkan warna komponen utama dan pendukung. Tema warna adalah warna yang playfull. Halini dipilih karena target user adalah kelompok usia 4-6 tahun yang belum mengenal banyak jenis warna (Gambar 5).
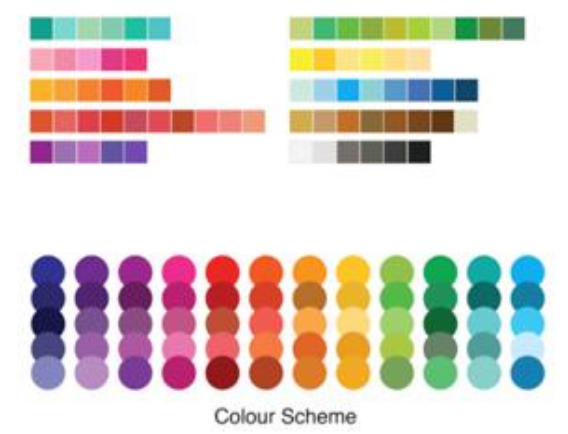

Gambar 5. Skema Warna

\section{H.Karakter}

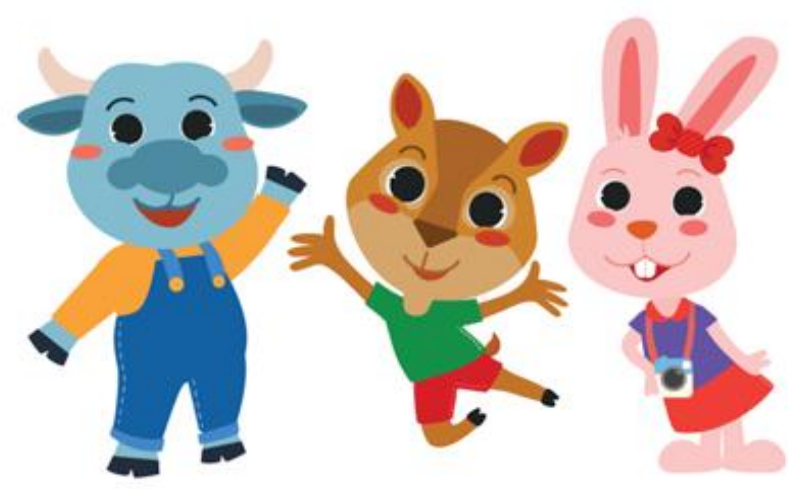

Gambar 6. Karakter Utama

Karakter yang digunakan pada ABC Petualang Nusantara adalah Kancil, Kerbau dan kelinci. Karakter binatang yang lucu mudah diterima oleh anak-anak. Gambar binatang dibuat lebih sederhana dengan tetap menampilkan karakteristik utamanya agar mudah dikenali oleh anak-anak maka gaya gambar kartun dipilih untuk mewujudkan karakter dari tokoh-tokohnya (Gambar 6).

Penjelasan nama sebagai berikut:

\section{a. Nama : Acil si Kancil}

Sifat : Ramah, pemberani, selalu ingin tahu dan adil

b. Nama : Bao-Bao si Kerbau

Sifat : Jenaka, suka makan dan polos

c. Nama : Cici si Kelinci

Sifat : Lincah dan Centil

Tabel 1. Konten buku aktivitas

\begin{tabular}{|c|c|c|c|c|}
\hline Provinsi & Kota & Icon & $\begin{array}{c}\text { Hewan } \\
\text { Endemik }\end{array}$ & Aktivitas \\
\hline \multirow{2}{*}{$\mathrm{NAD}$} & \multirow{2}{*}{ Aceh } & $\begin{array}{l}\text { Tugu Kilomer } 0 \\
\text { Indonesia }\end{array}$ & Tapir & \multirow{2}{*}{$\begin{array}{c}\text { Tarik } \\
\text { Teh Tarik }\end{array}$} \\
\hline & & $\begin{array}{c}\text { Taman Nasional } \\
\text { Leuser }\end{array}$ & $\begin{array}{l}\text { Bajing } \\
\text { Terbang }\end{array}$ & \\
\hline $\begin{array}{l}\text { Sumatera } \\
\text { Utara }\end{array}$ & Medan & $\begin{array}{c}\text { Danau Toba \& } \\
\text { Samosir }\end{array}$ & $\begin{array}{l}\text { Burung Beo } \\
\text { Mentawai }\end{array}$ & $\begin{array}{l}\text { Tracing } \\
\text { Angka, }\end{array}$ \\
\hline $\begin{array}{c}\text { Riau } \\
\text { Kepulauan }\end{array}$ & Riau & $\begin{array}{l}\text { Candi Muara } \\
\text { Takus }\end{array}$ & Binturong & $\begin{array}{l}\text { Puzzle } \\
\text { Sticker }\end{array}$ \\
\hline $\begin{array}{l}\text { Sumatra } \\
\text { Barat }\end{array}$ & Padang & Jam Gadang & $\begin{array}{c}\text { Kijang } \\
\text { Sumatera, } \\
\text { Owa } \\
\text { (Siamang) }\end{array}$ & $\begin{array}{l}\text { Mengenal } \\
\text { Waktu \& } \\
\text { Aktivitas }\end{array}$ \\
\hline Jambi & Jambi & $\begin{array}{l}\text { Taman Nasional } \\
\text { Gunung Kerinci }\end{array}$ & $\begin{array}{l}\text { Buaya, } \\
\text { Kambing, } \\
\text { Harimau } \\
\text { Sumatera }\end{array}$ & $\begin{array}{l}\text { Mencari } 8 \\
\text { Perbedaan }\end{array}$ \\
\hline Bengkulu & Bengkulu & Hutan Tropis & $\begin{array}{l}\text { Beruang } \\
\text { Madu }\end{array}$ & Maze Puzzle \\
\hline \multirow{2}{*}{$\begin{array}{l}\text { Sumatera } \\
\text { Selatan }\end{array}$} & \multirow[b]{2}{*}{ Palembang } & \multirow{2}{*}{$\begin{array}{l}\text { Jembatan Ampera } \\
\text { \& Sungai Musi } \\
\text { (malam) }\end{array}$} & $\begin{array}{l}\text { Ikan Belida, } \\
\text { Celurut Air }\end{array}$ & Stickering \\
\hline & & & & $\begin{array}{c}\text { Awan, Ikan, } \\
\text { Kerang, } \\
\text { Ban, Getek }\end{array}$ \\
\hline $\begin{array}{l}\text { Bangka } \\
\text { Belitung }\end{array}$ & $\begin{array}{l}\text { Pangkal } \\
\text { Pinang }\end{array}$ & Pantai Pasir Putih & Tringgiling & Mewamai \\
\hline Lampung & $\begin{array}{l}\text { Bandar } \\
\text { Lampung }\end{array}$ & $\begin{array}{l}\text { Sekolah Gajah } \\
\text { Way Kambas }\end{array}$ & $\begin{array}{c}\text { Gajah } \\
\text { Sumatera }\end{array}$ & $\begin{array}{l}\text { Tracing } \\
\text { Huruf A-z }\end{array}$ \\
\hline
\end{tabular}




\begin{tabular}{|c|c|c|c|}
\hline No & Aktivitas & Deskripsi & Manfaat dan Tujuan \\
\hline 1 & Kotak Misteri & $\begin{array}{l}\text { Membangun dan mewarnai puzzle } \\
\text { 3D jembatan Ampera. }\end{array}$ & $\begin{array}{l}\text { Mengenalkan ikon yang ada di Indonesia } \\
\text { - Mengasah kemampuan motorik halus pada anak } \\
\text { - Mengasah kemampuan ketrampilan dan kreativitas anak dengan mewarnai } \\
\text { Meningkatkan konsetrasi koordinasi antara mata tangan. }\end{array}$ \\
\hline 2 & Kartu Bergambar ABC & $\begin{array}{l}\text { Sekumpulan kartu yang berisikan } \\
\text { kosakata tentang Indonesia. }\end{array}$ & $\begin{array}{l}\text { - Mengenalkan kosakata tentang hal-hal baru yang ada di sekitar lingkungan } \\
\text { - Mengenalkan dan membantu } \\
\text { anak menghafal Alfabet A-Z } \\
\text { - Melatih kemampuan Menulis } \\
\text { - Mengasah memori anak }\end{array}$ \\
\hline 3 & Mari Mewarnai & $\begin{array}{l}\text { Buku yg berisikan } 10 \text { lembar } \\
\text { gambar outline untuk diwarnai. }\end{array}$ & $\begin{array}{l}\text { - Mengembangkan kemampuan motorik halus dan konsentrasi } \\
\text { pada anak } \\
\text { - Melatih koordinasi antara mata dan otot tangan } \\
\text { - Membantu membuat target dan menyelesaikan masalah } \\
\text { - Media untuk mengungkapkan ekspresi anak lewat seni }\end{array}$ \\
\hline 4 & Kue Jajanan Pasar & $\begin{array}{l}\text { Tingkatkan imajinasi anak dengan } \\
\text { belajar membuat serta menyusun } \\
\text { kue jajanan pasar tiruan yang } \\
\text { terbuat dari homemade playdough. }\end{array}$ & $\begin{array}{l}\text { - Melatih kreativitas dan imajinasi anak } \\
\text { - Mengasah kemampuan dasar seperti motorik halus serta koordinasi antara } \\
\text { penglihatan dengan otot tangan } \\
\text { - Memberikan efek mengurangi stress pada anak } \\
\text { - Meningkatkan konsetrasi dan koordinasi mata dan tangan. }\end{array}$ \\
\hline 5 & Aku Membuat Pelangi & $\begin{array}{l}\text { Belajar mengenal warna dan } \\
\text { melatih kreativitas dengan } \\
\text { menyortir warna, membentuk } \\
\text { pelangi. }\end{array}$ & $\begin{array}{l}\text { - Mengantarkan anak } \\
\text { - mengekspresikan estetika } \\
\text { - Melatih koordinasi mata dan otot tangan anak } \\
\text { - Melatih motorik halus } \\
\text { - Mendorong berpikir dan memecahkan masalah }\end{array}$ \\
\hline 6. & Papan Aktivitasku & $\begin{array}{l}\text { Papan Bagan pekerjaan atau } \\
\text { perilaku yang ditanggung jawabkan } \\
\text { kepada anak, dan bila memenuhi } \\
\text { poin akan mendapatkan hadiah. }\end{array}$ & $\begin{array}{l}\text { - Mengajak anak untuk menerapkan kedisiplinan dan kemandirian untuk } \\
\text { melakukan kebiasan dasar sehari-hari seperti bangun pagi } \\
\text { - Mendekatkan anak ke hal dan norma kebaikan } \\
\text { - Membiasakan anak untuk berinteraksi dan bersosialisai. }\end{array}$ \\
\hline
\end{tabular}

\section{Packaging}

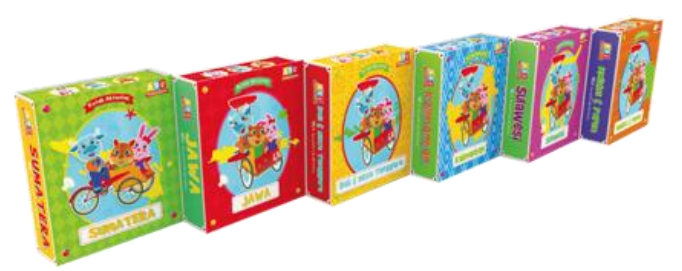

Gambar 7. Kotak packagingABC Petualang

Packaging yang akan digunakan adalah menggunakan dengan bahan duplek yang dibalut dengan stiker vinil. Penggunaan dua material ini bermaksud agar packaging dapat awet, multifungsi namun tetap aman untuk anak-anak (Gambar 7).

\section{J. Usability Testing}

Proses Usability Testing Protype atau user testing dilakukan di daerah Mojo kota Surabaya pada hari Minggu, 13 Januari 2019 (Gambar 8).

Dari hasil usability testing tersebut, dapat disimpulkan bahwa:

a. Anak-anak lebih suka jika melakukan aktivitas jika diawasi atau ditemani oleh orang tua

b. Anak-anak lebih suka jika melakukan aktivitas bersamasama (grup)

c. Dalam setiap aktivitas dapat menghabiskan waktu 45 menit sampai 2 jam

d. Anak-anak mulai tidak konsentrasi dan membutuhkan istirahat di jam ke 3

e. Anak-anak sangat suka jika setiap melakukan aktivitas diberi awarding walaupun hanya sekedar tepuk tangan

f. Anak-anak penasaran dengan membuka dahulu semua isi kotak, lalu memulai dengan memilih dari salah satu aktivitas

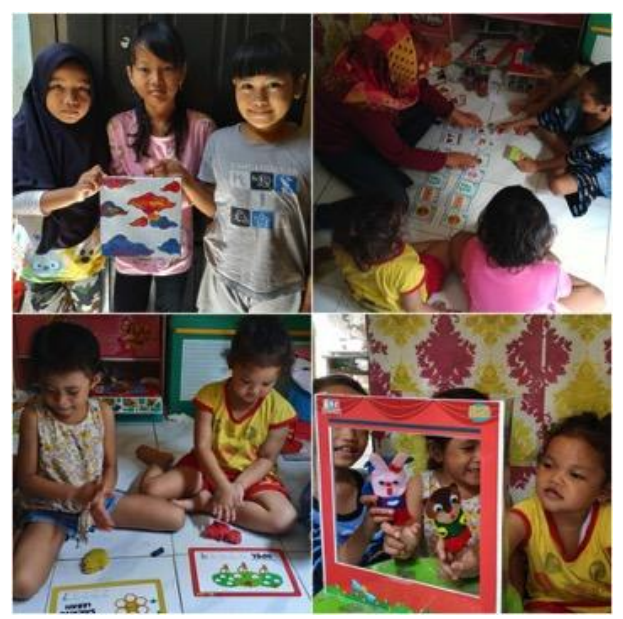

Gambar 8. Kotak packagingABC Petualang

\section{KESIMPULAN/RINGKASAN}

Kotak aktifitas ABC Petualang Nusantara adalah sebuah media dimana diharapkan adanya peluang untuk membuat media non-gadged yang memiliki manfaat agar dapat meningkatkan kecerdasan kemampuan dasar anak-anak sebagai user atau pengguna. Bukan hanya kecerdasan kognitif, afektif dan psikomotorik anak. Tujuan lain dari media ini adalah meningkatkan kemampuan sosial anak dengan orang tua maupun teman-temannya. Adanya penelitian ini adalah pelengkap dari penelitian tentang media edukasi anak usia dini dan diharapkan dapat dikembangkan media lain dengan tujuan membantu mengembangkan kemampuan dasar anak lainnya. 
Diajeng Rachmi Andini dan Raditya Eka Rizkiantono

Perancangan Kotak Aktivitas ABC Petualang Sebagai Media Bermain dan Perkembangan Dasar Anak Pra-Sekolah

\section{DAFTAR PUSTAKA}

[1] Anggara, Panji. "Kurangi Gadget, Kenalkan Mainan Tradisional” Metropolis Jawa Pos 31 Januari 2014: 36.

[2] Arntson, Amy. 2011. Graphic Design Basic, Sixth Edition. Wadsworth. Boston

[3] Beaty J. Janice.1994. Observatory Development of Your Child (Third Edition) .

[4] Cliff, Stafford. 1999. 50 Secrets of Great Design Packaging. Rockport
[5] Cohen, Sherm. 2006.Cartooning: Character Design (How to Draw \& Paint)

[6] Diana Mutiah. 2010. Psikologi Bermain Anak Usia Dini. Jakarta: Kencana. aktivitas.2.

[7] Drs. Usep Kustiawan. 2013. Perkembangan Media Pembelajaran Anak Usia Dini. Jakarta: Gunung Samudera

[8] Nguyen, Angela. 2017. How to Draw Cute Stuff: Draw Anything and Everything in the Cutest Style Ever! Sterling Children's 